Check for updates

Cite this: RSC Adv., 2019, 9, 38246

Received 15th August 2019

Accepted 15th November 2019

DOI: $10.1039 / \mathrm{c} 9 \mathrm{ra06389g}$

rsc.li/rsc-advances

\section{Self-assembled pearl-necklace patterned upconverting nanocrystals with highly efficient blue and ultraviolet emission: femtosecond laser based upconversion properties $\uparrow$}

\author{
Monami Das Modak, ${ }^{\mathrm{b}}$ Ganesh Damarla, ${ }^{\mathrm{c}}$ Somedutta Maity, ${ }^{\mathrm{b}}$ Anil K. Chaudhary ${ }^{\mathrm{c}}$ \\ and Pradip Paik (iD *ab
}

\begin{abstract}
This work reports new findings on the formation of a pearl-necklace pattern in self-assembled upconverting nanocrystals (UCN-PNs) which exhibit strong upconversion emission under an NIR excitation source of a femtosecond laser (Fs-laser). Each nano-necklace consists of several upconversion nanoparticles (UCNPs) having a size ca. $10 \pm 1 \mathrm{~nm}$. UCN-PNs are arranged in a selforganized manner to form necklace type chains with an average length of $140 \mathrm{~nm}$ of a single row of nanoparticles. Furthermore, UCN-PNs are comprised of UCNPs with an average interparticle separation of ca. $4 \mathrm{~nm}$ in each of the nanonecklace chains. Interestingly, these UCN-PNs exhibit high energy upconversion especially in the UV region on interaction with a $140 \mathrm{Fs}$-laser pulse duration at $80 \mathrm{MHz}$ repetition rate and intense blue emission at $450 \mathrm{~nm}$ on interaction with a $900 \mathrm{~nm}$ excitation source is obtained. The preparation of self-assembled UCNPs is easy and they are very stable for a longer period of time. The emission (fluorescence/luminescence) intensity is very high which can make them unique in innumerable industrial and bio-applications such as for disease diagnosis and therapeutic applications by targeting the infected cells with enhanced efficiency.
\end{abstract}

\section{Introduction}

Upconverting nanocrystals are attractive due to several unique properties and for their applications in materials, materials science, industrial applications for designing solar cells, sensors etc. and for biomedical medical applications. ${ }^{\mathbf{1 , 2}}$ Rareearth upconverting materials have been demanded as they are the best energy upconverting (NIR-to-visible) materials ever known, therefore currently researchers are focusing on their design, synthesis and spectroscopic properties. Furthermore, upconverting materials possess potential uses in biological labeling and bio-assays and their extent of uses has increased remarkably with time..$^{3-7}$ All these unique features drive us to synthesize self-assembled UCNPs having strong upconversion emission. To the best of our knowledge, self-assembled pearlnecklace type upconverting nanoparticles (UCN-PNs) are never known. A report was found where UCNPs were impregnated in

${ }^{a}$ School of Biomedical Engineering, Indian Institute of Technology, BHU, Varanasi 221 005, UP, India.E-mail: paik.bme@iitbhu.ac.in; pradip.paik@gmail.com

${ }^{b}$ School of Engineering Sciences and Technology, University of Hyderabad, Hyderabad 500 046, Telangana, India

${ }^{c}$ Advanced Center of Research in High Energy Materials, University of Hyderabad, Hyderabad, Telangana, 500 046, India

$\dagger$ Electronic supplementary information (ESI) available. See DOI: 10.1039/c9ra06389g porphyrin dendrimers. ${ }^{8}$ In this work we are enabled to prepare self-assembled UCNPs in in situ condition without incorporating any external polymeric components. The as-prepared UCN-PNs have been formed by consuming all precursors into solid crystal nuclei as white precipitates at lower reaction temperature and then with increasing the reaction temperature crystal growth occurred followed by the formation of UCN-PNs. The as-prepared UCN-PNs have excellent dispersibility in nonpolar solvent (e.g., cyclohexane) and are stable for more than a year. As UCN-PNs exhibit excellent upconversion emission under $980 \mathrm{~nm}$ NIR excitation source and 140 femtosecond pulse duration at $80 \mathrm{MHz}$ repetition rate, there is a vast ambit for using them in complex biolabeling by tuning their spectral properties. Further, for present available systems there are several draw backs in achieving good efficiency for the DNA detection, ${ }^{9}$ bio-imaging, ${ }^{10}$ sensors and fluorophores, ${ }^{\mathbf{1 1 - 1 3}}$ analytes and several other important biomedical applications such as for the treatment of cancers ${ }^{\mathbf{1 4 - 1 7}}$ which can be improved by using UCN-PNs.

Self-assembled materials can be obtained from nature to the laboratory. Self-assembly in living system is biologically controlled whereas; self-assembly formation in laboratory is controlled artificially. The assembly of nanomaterials is purely represented by non-covalent bonding and controlled both by kinetic and thermodynamically. Inside laboratory self- 
assembly processes are used for designing the artificial nanostructures, such as for assembling proteins, peptides, nucleotides, supramolecular biopolymers etc. and they have myriad applications in biomedicals for developing artificial membranes and for various biofunctions. ${ }^{\mathbf{1 8 - 2 0}}$ Self-assembly of various inorganic (metals/hybrids) nanoparticles is well known. ${ }^{21-23}$ The formation of self-assembled necklace type nanostructures is very much interesting in the area of modern nanotechnology. Necklace nanostructures of UCNPs can exhibit unique properties with their associated building blocks (nanoparticles below $10 \mathrm{~nm}$ ). The self-assembled architectures of nano sized UCNPs can offer a potential platform for future applications, especially in nonlinear optical property based nanotechnology. Self-assembled nanobuildings have become the most exciting nanometre-sized branched architectures, which are formed by repeating nanoscopic building blocks. Hence, the effort of forming such self-assembled UCN-PNs can be considered as spontaneous assembly of branched building blocks of nanoparticles. Usually, the interactions between the molecules associated with such net-work structures can be referred to the supramolecular chemistry, ${ }^{\mathbf{2 4}}$ where non-covalent interactions play major roles between molecules. UCNPs can also be used for the photodynamic therapy (PDT) by which cancer can be treated. On excitation of UCN, in presence of oxygen, photosensitized molecules can be activated with an appropriate excitation wavelength for producing singlet oxygen species $\left({ }^{1} \mathrm{O}_{2}\right)$ and reactive oxygen species (ROS) which can kill the nearby cancer cells. In PDT, UV- vis light can excite the photosensitizers. For such strategy, UCNPs have shown excellent promising candidate as after exposing them to NIR radiation, emission of UV and or visible light can occur. ${ }^{25-27}$ Further, to treat the cancer, recently a sacrificial template strategy has been developed by Huang et al. ${ }^{28}$ to fabricate yolkshell nanoparticles combination with UCNPs and CuS nanoparticles which demonstrated very efficient energy transfer between the UCNPs and CuS. The as prepared UCNPs@CuS nanoparticles showed higher ability for productions of $\mathrm{OH}$ radicals, ROS and ${ }^{1} \mathrm{O}_{2}$ and exhibits an enhanced photothermal effect while exposing to NIR light kill the cancer cell. Uniform ultrasmall-sized UCNPs ( $\mathrm{NaGdF}_{4}$ nanocrystals) below $10 \mathrm{~nm}$ was also been prepared by Liu et al. ${ }^{29}$ using PEG-PAA-di-block copolymer (byg ligand exchange approach) and used for the imaging.

In the above line, present work is focused on the synthesis of self-assembled UCN-PNs and their upconversion behavior. The upconversion luminescences of self-assembled UCN-PNs are interesting which have been studied here. In a set of experiments, the upconversion behaviors of UCN-PNs have been studied with femtosecond (Fs) laser (140 femtosecond pulse duration at $80 \mathrm{MHz}$ repetition rate) along with CW-980 nm NIR. Further, visible-to visible photoluminescence has also been studied. The NIR to UV/vis upconversion properties is also observed for UCN-PNs which is represented here in detail. At the end, probable mechanisms for the visible-visible/CW-980 NIR/Fs-laser based upconversions with energy band diagrams for different emissions have been elucidated.

\section{Experimental section}

\subsection{Materials}

Aqueous solutions of three lanthanide precursors such as, $\mathrm{Cl}_{3}$ $\mathrm{Y} \cdot 6 \mathrm{H}_{2} \mathrm{O}, \mathrm{Cl}_{3} \mathrm{Yb} \cdot 6 \mathrm{H}_{2} \mathrm{O}, \mathrm{Cl}_{3} \mathrm{Er} \cdot 6 \mathrm{H}_{2} \mathrm{O}$ (99\%), octadecene (90\%), methanol (98\%) (Sigma Aldrich) and oleic acid $\left(\mathrm{C}_{18} \mathrm{H}_{34} \mathrm{O}_{2}, 65 \%\right)$, ammonium fluoride $\left(\mathrm{NH}_{4} \mathrm{~F} ; 95 \%\right)$, sodium hydroxide $(\mathrm{NaOH}$, 97\%), from Qualigens, Kemphasol and SDFCL, respectively were received and used in those forms without further purifications.

\subsection{Synthesis method}

UCN-PNs were synthesized by solvothermal decomposition process of lanthanide precursors and technical grade chemicals. Three different precursors were prepared in presence of de-ionized $\mathrm{H}_{2} \mathrm{O}$. These three precursors were then dried at 110-115 ${ }^{\circ} \mathrm{C}$. Further, in decomposed compound organic solvents (oleic acid and octadecene) were added and stirred at $140{ }^{\circ} \mathrm{C}$. Then it was cooled down to room temperature. Then, a solution of $\mathrm{CH}_{3} \mathrm{OH}, \mathrm{NH}_{4} \mathrm{~F}$ and $\mathrm{NaOH}$ was added at room temperature and stirred to remove excess oxygen and water, and heated further to $340{ }^{\circ} \mathrm{C}$ (rate of $20{ }^{\circ} \mathrm{C} \mathrm{min}^{-1}$ ). Entire synthesis was performed under argon gas atmosphere and a vacuum condition was maintained at $100{ }^{\circ} \mathrm{C}$. Next day, the synthesized sample was collected with acetone via centrifugation with $9000 \mathrm{rpm}$ for 15-20 min. The precipitated product was collected by dispersing with cyclohexane $(40 \mathrm{ml})$. Finally it was washed with ethanol and D.W. (1:1) for 3-4 times. The resulted solution was preserved in a container as its colloidal form. The self-assembled UCN-PNs are stable for more than a year. Surprisingly, no agglomeration or settling was found, however after a couple of weeks the white particles seemed to be settled clearly at the bottom of container and it can be readily dispersed at room temperature and subsequent characterization revealed that necklace net-work structures are persist for more than a year. The detail of synthesis method was filled for an Indian Patent (ref: TEMP/E-1/21065/2017CHE, dated: 14/06/2017).

\subsection{Characterizations}

Transmission Electron Microscopy (TEM) and High Resolution Transmission Electron Microscopy (HRTEM) (model FEI TecnaiG2-TWIN $200 \mathrm{KV}$ ) were used to study the morphology and sizes of the as-synthesized UCN-PNs. Energy Dispersive X-ray Analysis (EDXA) were performed for the elemental analysis. Crystal structure was revealed using X-ray diffraction pattern (XRD with Co K $\alpha$-radiation). The solid state structure present in UCN-PNs was analysed with Raman Spectroscopy (Wi-Tec, alpha 300), upconversion fluorescence study was performed through fluorescence spectrophotometer (Hitachi, F-4600) attached with a NIR laser source $(\lambda=980 \mathrm{~nm})$ externally. Further, photoluminescence was performed with $450 \mathrm{~nm}$ excitation source using PL mode of Multimode Reader (Synergy H4 Hybrid Reader). A Ti-Sapphire tunable oscillator was used with femtosecond (Fs) laser-pulses and the experimental set-up of Fslaser has provided in ESI File. $\dagger$ 


\section{Results and discussion}

The self-assembly of nanonecklace network formations and sizes of the as-prepared UCNPs have been shown in Fig. 1(a)-(d) with different magnification TEM images. TEM was performed using the colloidal solution of UCN-PNs on copper grid (200 mesh, carbon coated). Fig. 1(a)-(c) confirm the self-assembled pearl necklace-type net-work formations of synthesized UCN particles. TEM images (Fig. 1(a)-(c)) show the caterpillar-like/ pearl chain type necklace formations at different magnification. Inset of Fig. 1(b) clearly shows the density of the particles for different chains. In Fig. 1(c), lengths of the chains have been shown clearly, where the dotted lines with different colour have been drawn for different chain lengths. Further, it can be noted that the chains are formed with a single row of nanoparticles without overlapping and the distance between two adjacent particles are nearly constant. Most of the regions throughout the sample are able to contain a uniform size of the particles. Overlapping between the particles is almost negligible due to the possible electrostatic interactions. The high crystallinity is confirmed by high resolution TEM images. Fig. 1(d) and (e) show a clear lattice fringes with inter-fringes $d$ of $0.31 \mathrm{~nm}$. The crystalline nature of the UCN-PNs further has been confirmed through the XRD analysis (shown in subsequent section). Fig. 1(f) shows the SAED pattern with clearly visible ring type diffraction pattern. Fig. 1(f) has further confirmed five diffraction planes such as (101), (220), (311), (400) and (331) which correspond to the formations of $\alpha$ - and major $\beta-\mathrm{NaYF}_{4}$ UCNPs. Fig. $1(\mathrm{~g})$ represents the average particle diameter and its distribution is found to be average $c a$., $10 \mathrm{~nm} \pm 1 \mathrm{~nm}$. Further, the length of nanonecklaces, number of particles per necklace and interparticle separation has also been calculated from TEM results. From Fig. 1(h)-(j), it can be confirmed that the average nanonecklace length of $140 \mathrm{~nm}$ which consists of 7-13 numbers of particles per necklace and interparticle distance observed to be $c a .4 \mathrm{~nm}$. X-ray diffraction study was performed to confirm the solid state crystalline structure and is shown in Fig. S1. $\dagger$ The peak positions that appeared are corresponding to the diffraction planes (101), (220), (311), (400) and (331), respectively. The $d$-spacing values have also been calculated and found to be 2.9 $\AA$, $2.0 \AA, 1.63 \AA, 1.43 \AA$ and $1.26 \AA$, respectively, which are matching for the $\alpha-/ \beta-\mathrm{NaYF}_{4}$ crystalline phases for UCNPs. ${ }^{30-32}$ The elemental analysis was performed through the Energy Dispersive X-ray Analysis (EDXA) (Fig. S2 $\dagger$ ) and confirms for the presence of the elemental Na, Y, F, Er and Yb (see Table S1†).

The upconversion fluorescence spectrum for UCN-PNs under $980 \mathrm{~nm}$ NIR CW laser-excitation source is shown in Fig. 2. During experiment the power density was maintained to 1000 $\mathrm{mW} \mathrm{cm} \mathrm{cm}^{-2}$. From Fig. 2, it can be observed that UCN-PNs exhibited a very strong upconversion emission. Intense emission bands with their maximum positions are appeared at $\lambda=$ $526 \mathrm{~nm}, 545 \mathrm{~nm}$ and $659 \mathrm{~nm}$ for the green emission (G), which are much higher in intensity (4.3 times) than that of the red emission band (R). Green emissions band appeared at $526 \mathrm{~nm}$ between $509 \mathrm{~nm}$ and $531 \mathrm{~nm}$ and at $545 \mathrm{~nm}$ between $532 \mathrm{~nm}$ and $570 \mathrm{~nm}$ are attributed to the transitions in the energy levels$2 \mathrm{H}_{11 / 2}, 4 \mathrm{~S}_{3 / 2}$ (excited energy levels) and $-4 \mathrm{I}_{15 / 2}$ (ground state energy level of $\mathrm{Er}^{3+}$ ion), respectively, through direct energy transferring modes from sensitizer ion $\left(\mathrm{Yb}^{3+}\right)$ to activator ion $\left(\mathrm{Er}^{3+}\right)$. A less intense (compared to the green emission) red emission bands at $659 \mathrm{~nm}$ (between 632-691 nm) has appeared with $4 \mathrm{~F}_{9 / 2}$ to $4 \mathrm{I}_{15 / 2}$ energy transfer which follows a less population in $4 \mathrm{~F}_{9 / 2}$ energy level through the energy transfer path $4 \mathrm{I}_{13 / 2} \rightarrow 4 \mathrm{~F}_{9 / 2}$. Herein, $4 \mathrm{I}_{13 / 2}$ level is populated with nonradiative relaxations between $4 \mathrm{I}_{11 / 2}$ and $4 \mathrm{I}_{13 / 2}$ energy levels. Further, very weak emission bands are observed at $\lambda=382 \mathrm{~nm}$, $411 \mathrm{~nm}$ and $497 \mathrm{~nm}$ corresponding to the energy transition modes, $4 \mathrm{G}_{11 / 2} / 2 \mathrm{H}_{9 / 2} \rightarrow 4 \mathrm{I}_{15 / 2}$ and $4 \mathrm{~F}_{5 / 2} \rightarrow 4 \mathrm{I}_{15 / 2}$, respectively. These weak emission bands are observed owing to the continuous of input source which excites the $\mathrm{Er}^{3+}$ ions sequentially to
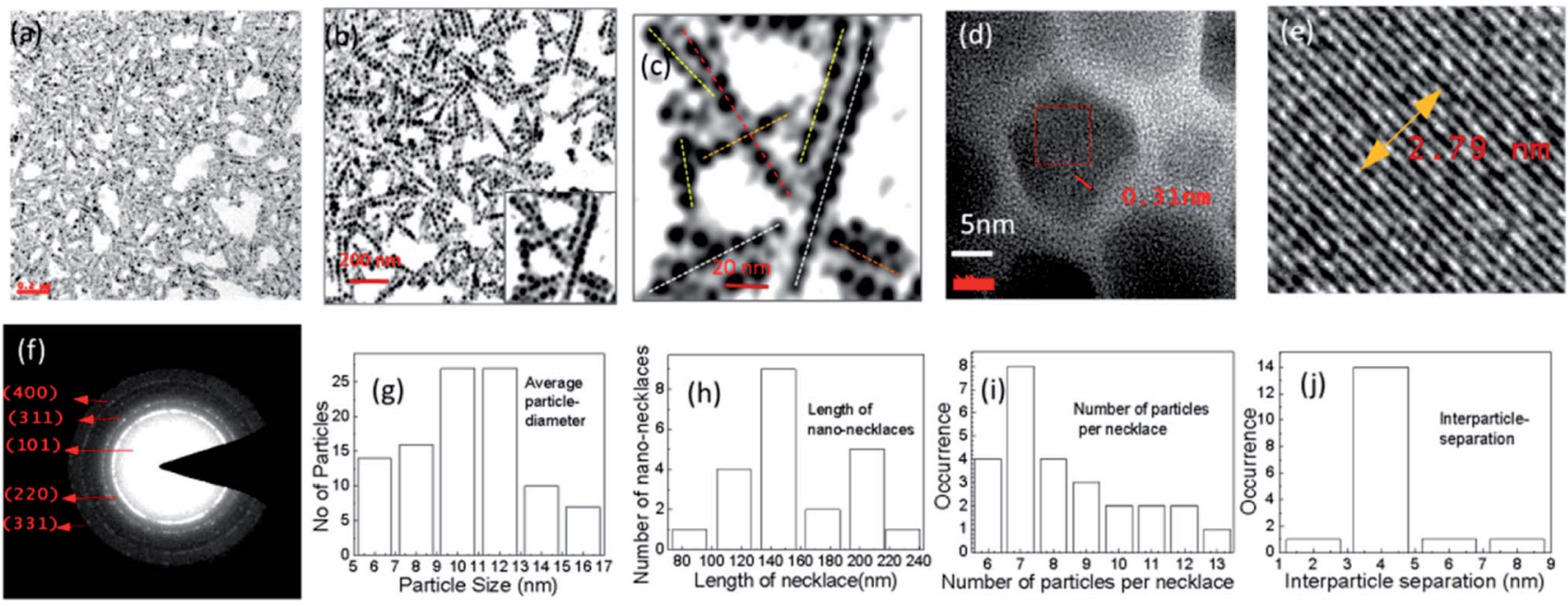

Fig. 1 TEM images of the synthesized colloidal-UCNPs (UCN-PNs at different magnifications). Panels: ( $a$ and $b)=200 \mathrm{~nm}$, inset in panel (b) shows the clear formation of pearl nanonecklaces $(c)=20 \mathrm{~nm}$, (d) and (e) = high resolution micrograph showing lattice fringes, $(\mathrm{f})=\mathrm{SAED}$ ring pattern, histogram of $(\mathrm{g})=$ particle diameter, (h) nano-necklace length, (i) total number of particles per necklace, (j) interparticle-separation. 

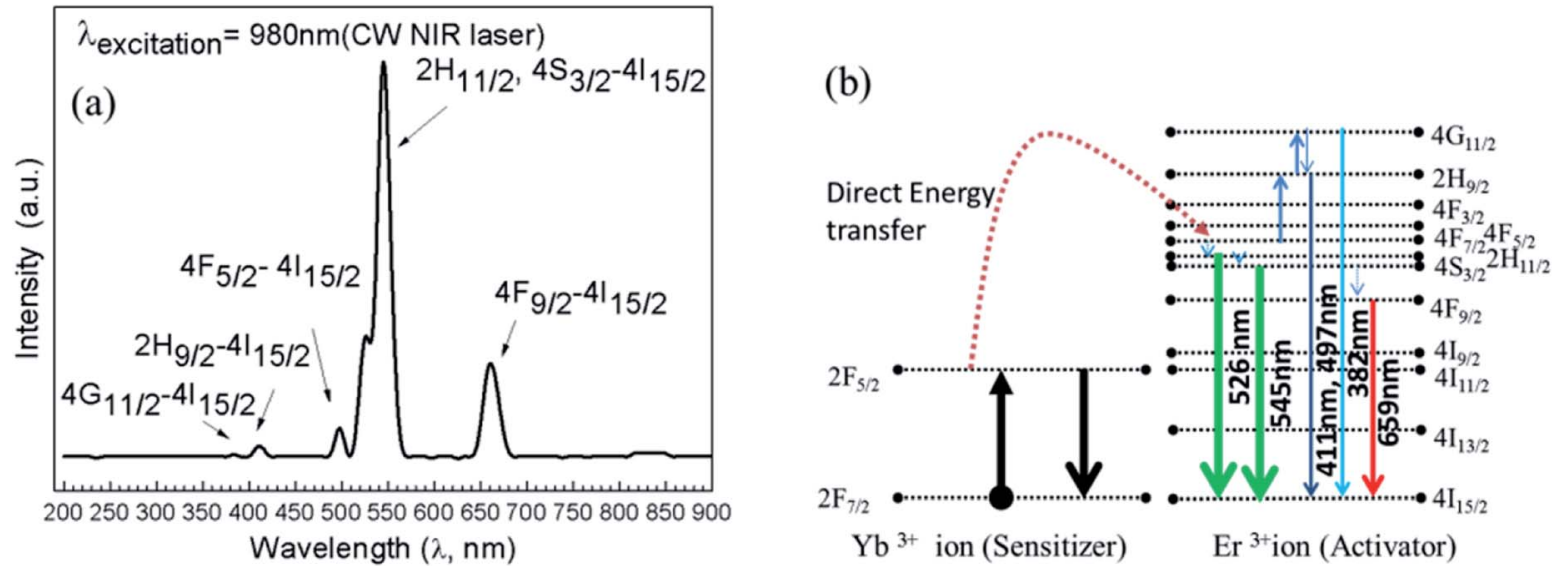

Fig. 2 (a) Upconversion emission spectrum examined with UCN-PNs colloidal solution (b) corresponding energy diagram, under 980 nm NIRlaser excitation source.

the next higher energy levels following the path $4 \mathrm{I}_{15 / 2} \rightarrow 4 \mathrm{I}_{11 / 2}$ $\rightarrow 4 \mathrm{~F}_{7 / 2} \rightarrow 4 \mathrm{G}_{11 / 2}$. It can be noted that, indirect energy transfers and cross relaxations resulted in very weak emission bands. ${ }^{30,33}$ It also can be noted that, for UCN particles $\left(\mathrm{NaYF}_{4}, \mathrm{Yb}^{3+} ; \mathrm{Tm}^{3+}\right)$, $\mathrm{Tm}^{3+}$ ion is responsible for blue emission $(440-500 \mathrm{~nm})^{30}$ following the energy transition paths, $1 \mathrm{D}_{2} \rightarrow 3 \mathrm{~F}_{4}$ and $1 \mathrm{G}_{4} \rightarrow$ $3 \mathrm{H}_{6}$. However, for our UCN-PNs, without introducing $\mathrm{Tm}^{3+}$ precursors we are able to achieve high intense blue emission which could be helpful as blue emitting nanophosphors and can be effective for designing biomedical devices and applications. ${ }^{34}$ In can be noted that, for the monodispersed UCNPs, highest intensity was obtained at $546 \mathrm{~nm}$ is 1853 a.u., whereas for self-assembled UCNP (UCN-PNs), highest intensity obtained at $546 \mathrm{~nm}$ is 3789 a.u. Hence, the enhancement of intensity (considering visible emissions at $546 \mathrm{~nm}$ ) is about $\sim 2$ times higher in UCN-PNs compared to the monodispersed UCNPs (see for experimental observations see Fig. $\mathrm{S} 7 \dagger$ ), where same amount (weight basis) of UCNPs were dispersed in a fixed volume of solvent.

It is very interesting to mention that $980 \mathrm{~nm}$ NIR excitation resulted weak blue emissive band (Fig. 2) and when we examined the sample with a couple of lower excitation wavelength sources as example, $\lambda=800-900 \mathrm{~nm}$, then a high intense blue emissions occurred at $450 \mathrm{~nm}$ corresponds to the energy transition path, $2 \mathrm{H}_{9 / 2} \rightarrow 4 \mathrm{I}_{15 / 2}$. Fig. 3(a) represents the emission spectra with their corresponding energy transitions under $900 \mathrm{~nm}$ excitation source and Fig. 3(b) represents the respective energy level diagram supported by direct energy transfers from $\mathrm{Yb}^{3+}$ to $\mathrm{Er}^{3+}$ ion.

The insets in Fig. 3(a) shows the visible blue emissions of UCN-PNs from the UCN-PNs sample kept in glass bottle and quartz cuvette, with direct irradiation of $200 \mathrm{~nm}$ wavelength source. Fig. 4(a) and (b) show the UCN-PNs solution (during synthesis) in stirring condition within reaction chamber and glass bottle and $4 \mathrm{c}$ shows blue emissions for the UCN-PNs just after washing, respectively. These UCN-PNs are stable at least for one year owing to their high surface zeta potential value $(\xi)$ of about $-55.49 \mathrm{mV}$ (Fig. S3†).
Fig. 5 shows the Raman spectrum for UCN-PNs, where the bands appeared at $260 \mathrm{~cm}^{-1}, 303 \mathrm{~cm}^{-1}, 364 \mathrm{~cm}^{-1}$ and $395 \mathrm{~cm}^{-1}$ (below $700 \mathrm{~cm}^{-1}$ ) confirm the formation of hexagonal-phases. ${ }^{35,36}$ Beyond $700 \mathrm{~cm}^{-1}$, the appearance of strong bands at $725 \mathrm{~cm}^{-1}, 2887 \mathrm{~cm}^{-1}$ and $3512 \mathrm{~cm}^{-1}$ are evidences for the presence of cubic-phases conjugated with oleic acid (capping agent). Thus both the results obtained from XRD and Raman confirmed the formation of UCN-PNs with major $\beta$-phase along with a less extent of $\alpha$-phase.

As reported earlier, the appearance of bands due to the presence of vibrational modes above $700 \mathrm{~cm}^{-1}$ are found very weak for the minute quantity of hexagonal crystalline phase in UCNPs. With the formation of $\alpha-\mathrm{NaYF}_{4}$ phase, the Ramanspectra broadened within 1384-1416 $\mathrm{cm}^{-1}$ and 1041$932 \mathrm{~cm}^{-1}$ along with two additional bands appeared in between 703-687 $\mathrm{cm}^{-1}$ and $279-260 \mathrm{~cm}^{-1} \cdot \cdot^{37,38}$ Relatively, weaker bands appeared between 700-1700 $\mathrm{cm}^{-1}$ and between 2820$2980 \mathrm{~cm}^{-1}$ due to the presence of capping agent (oleic acid). ${ }^{39}$ Weakly intense Raman bands appeared between $1073 \mathrm{~cm}^{-1}$ and $1445 \mathrm{~cm}^{-1}$ confirm the presence of asymmetry $\mathrm{C}-\mathrm{O}-\mathrm{C}$ and $\mathrm{CH}_{3}$ stretching, respectively, whereas presence of $\mathrm{C}-\mathrm{CH}_{3} / \mathrm{C}-\mathrm{H} / \mathrm{O}-\mathrm{H}$ bonds are confirmed by the medium intense bands appeared near $2885 \mathrm{~cm}^{-1}$ and $3620 \mathrm{~cm}^{-1}$. It is also noticed that the, bands appeared between $3300-3500 \mathrm{~cm}^{-1}$ are ascribed to the $(-\mathrm{N}-\mathrm{H})$ vibration band which contributes for the formations of selfassembled nano necklace net-work structures between UCNPs (full range Raman spectrum has provided in ESI Fig. S4 $\dagger$ ). Further, the FTIR spectrum of UCN-PNs is shown in Fig. S5 $\dagger$ which confirms the presence of various functional groups including $\mathrm{N}-\mathrm{H}$ bending vibration at $1558 \mathrm{~cm}^{-1}$ and other oleic acid-capped groups at $2921 \mathrm{~cm}^{-1}, 2850 \mathrm{~cm}^{-1}$ appearing with highest intensity attached with the UCN-PNs. ${ }^{\mathbf{4 0 , 4 1}}$

However, the present analysis gives us a clear indication of $\alpha$ and $\beta$-phase formation within UCN-PNs crystals and is further supported by the TEM and XRD results (Fig. 1(f) and S1†). The presence of two phases effectively influences for the inhancement of upconversion efficiency which has been discussed in the subsequent sections. 


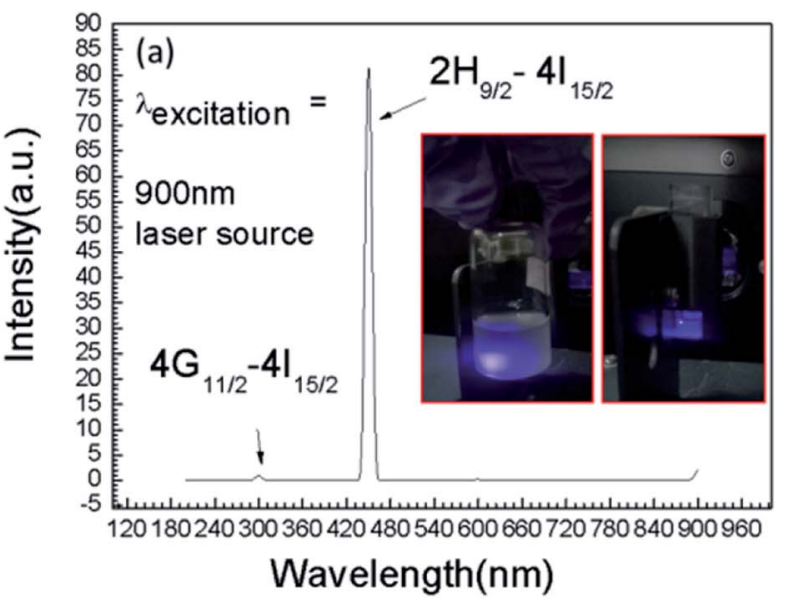

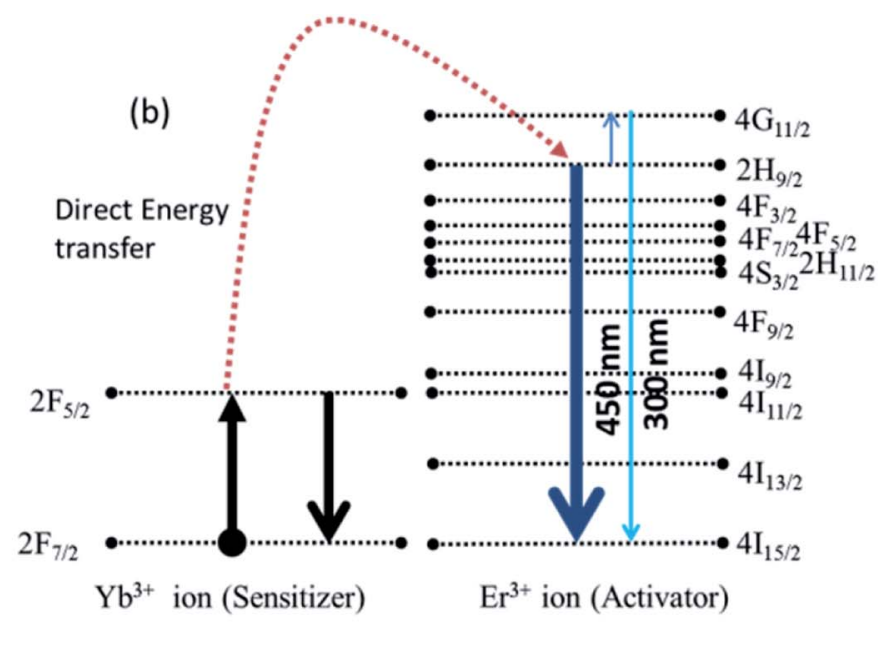

Fig. 3 (a) Upconversion emission spectrum obtained with $\lambda_{\text {excitation }}$ of $900 \mathrm{~nm} \mathrm{CW}$ laser source. Inset of (a) is showing the blue emission from UCN-PNs and (b) is the corresponding energy band diagram.

PL of the UCN-PNs has also been studied. From PL study (Fig. 6), a visible-visible wavelength conversion emission bands are observed. The excitation wavelength source was used with $\lambda=450 \mathrm{~nm}$ and the observed emissions obtained here are in between $400-650 \mathrm{~nm}$. This is an interesting observation which has never been reported even for any type of UCNPs. It can be noted that for all rare earth materials and for UCNPs only NIR to visible upconversion was reported. ${ }^{\mathbf{4 2 , 4 3}}$ In another study, NIR-NIR upconversion was also reported previously in literature. ${ }^{\mathbf{3 4 4 4 - 4 7}}$ However, visible to visible wavelength conversion is a unique phenomenon observed for UCN-PNs, and to the best of our knowledge it has never been reported. For UCN-PNs, the observed emission bands with their highest band positions appeared at $422 \mathrm{~nm}, 462 \mathrm{~nm}, 520$ $\mathrm{nm} / 546 \mathrm{~nm}, 572 \mathrm{~nm}$ and $638 \mathrm{~nm}$, correspond to the energy transfers as, $2 \mathrm{H}_{9 / 2} \rightarrow 4 \mathrm{I}_{15 / 2}$ and $2 \mathrm{H}_{11 / 2} / 4 \mathrm{~S}_{3 / 2} \rightarrow 4 \mathrm{I}_{15 / 2}$ and $4 \mathrm{~F}_{9 / 2}$ $\rightarrow 4 \mathrm{I}_{15 / 2}$, respectively. The energy level diagram correspond to the PL spectra (Fig. 6(a)) is shown in Fig. 6(b). The band energy diagram includes two incidences of direct energy transfers between two rare earth ions $\left(\mathrm{Yb}^{3+}\right.$ and $\left.\mathrm{Er}^{3+}\right)$ and passes through several cross relaxations and, radiative and nonradiative decays that resulted in a number of emission bands. They are as follows:

Energy transfer-I occurred for $2 \mathrm{~F}_{5 / 2} \rightarrow 2 \mathrm{H}_{9 / 2}$ transition, energy transfer-II occurs from $2 \mathrm{~F}_{5 / 2} \rightarrow 4 \mathrm{~F}_{9 / 2}$ resulting efficient blue and red emissions with $2 \mathrm{H}_{9 / 2} \rightarrow 4 \mathrm{I}_{15 / 2}$ and $4 \mathrm{~F}_{9 / 2} \rightarrow 4 \mathrm{I}_{15 / 2}$ transitions, respectively. Whereas, the green emissions occurred with four non-radiative relaxations such as, $2 \mathrm{H}_{9 / 2} \rightarrow 4 \mathrm{~F}_{3 / 2}, 4 \mathrm{~F}_{3 / 2} \rightarrow 4 \mathrm{~F}_{5 / 2}$, $4 \mathrm{~F}_{5 / 2} \rightarrow 4 \mathrm{~F}_{7 / 2}, 4 \mathrm{~F}_{7 / 2} \rightarrow 2 \mathrm{H}_{11 / 2}$ or $4 \mathrm{~S}_{3 / 2}$ from $2 \mathrm{H}_{9 / 2}$ level with $2 \mathrm{H}_{11 / 2} / 4 \mathrm{~S}_{3 / 2} \rightarrow 4 \mathrm{I}_{15 / 2}$ transitions (see Fig. 6(b)).

\subsection{Study the upconversion luminescence with femtosecond} (Fs)-laser source with different excitation wavelengths

Interaction of UCN-PNs with femtosecond-laser (Fs) results in high energy upconversion emissions under five different excitation wavelengths, such as $\lambda=940 \mathrm{~nm}, 950 \mathrm{~nm}, 960 \mathrm{~nm}$,
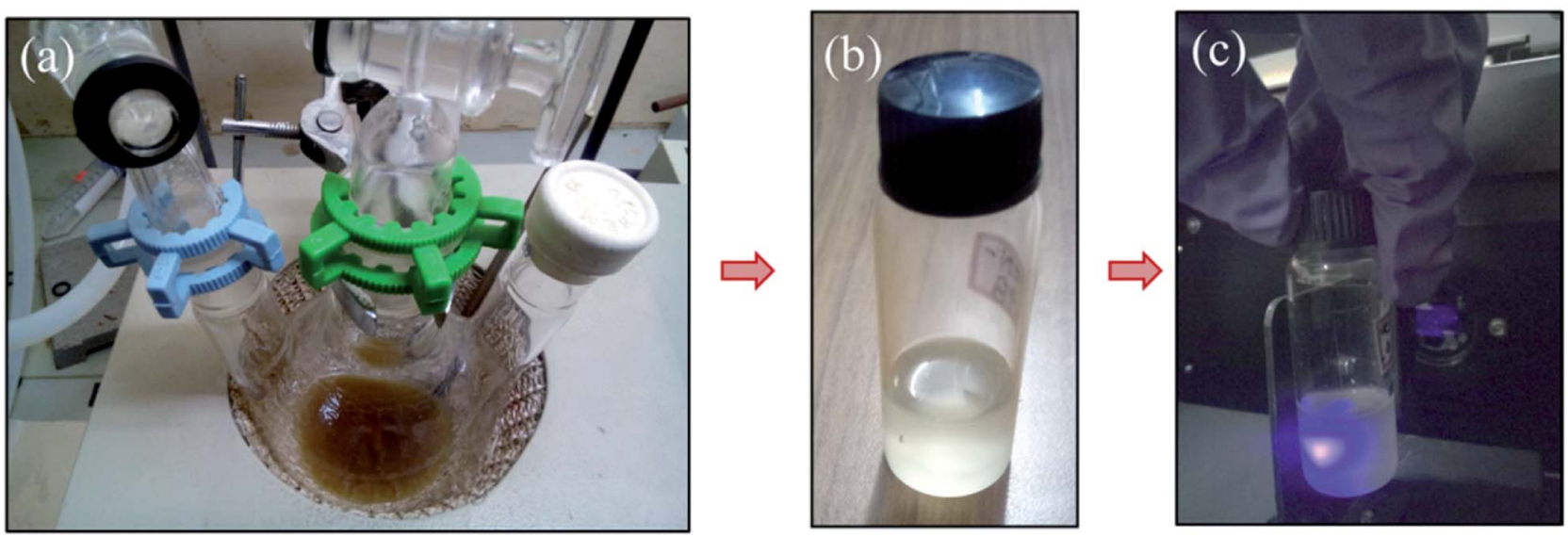

Fig. 4 (a) Image is captured during synthesis (stirring condition) of UCN-PNs at high reaction temperature $\left(\sim 330-340{ }^{\circ} \mathrm{C}\right)$ with $1 \mathrm{~h} 53 \mathrm{~min}$ reaction time (b) UCN-PNs colloidal sample and (c) intense blue emission in sample glass bottle, after washing done completely. 

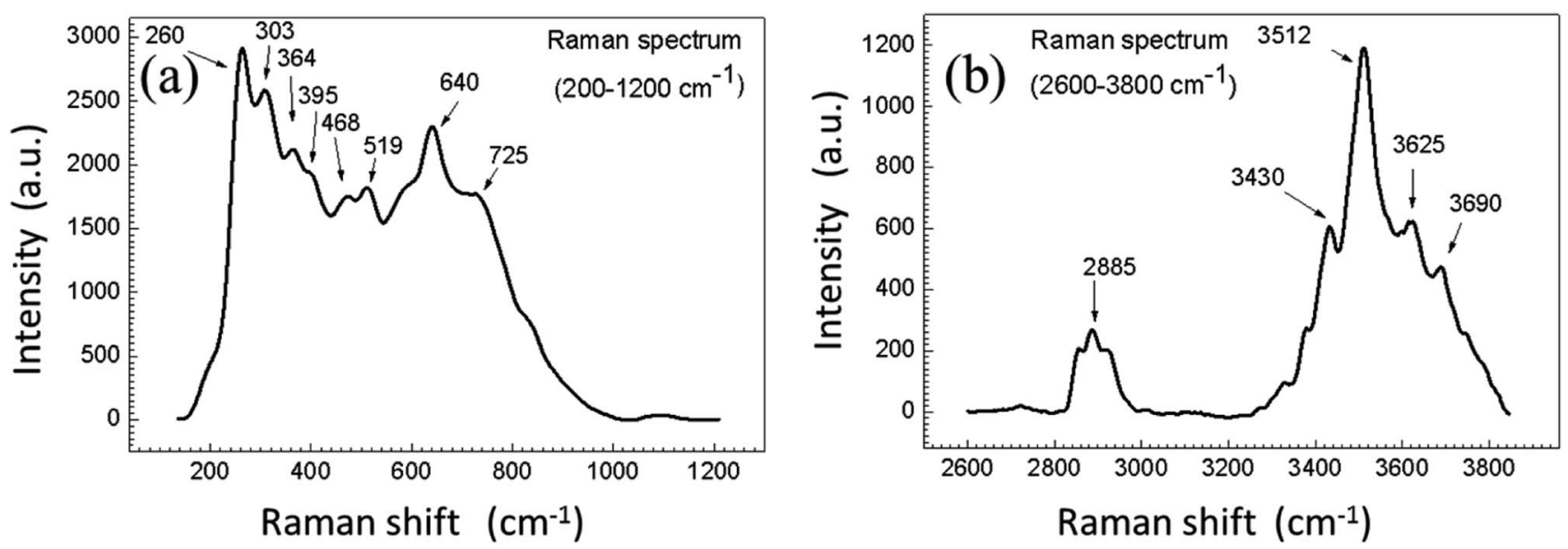

Fig. 5 (a) Raman spectrum between 200-1200 nm, (b) Raman spectrum between 2600-3800 nm, confirm the presence of both cubic ( $\alpha$ ) and beta ( $\beta$ ) phases in sample. The measurement was recorded at room temperature. The entire spectrum is shown in ESI (see Fig. S4 $\dagger$ ).

$970 \mathrm{~nm}$ and $980 \mathrm{~nm}$. Each of the incident pump wavelength has yielded distinct emissions in both UV and visible regions. The emission spectra along with their corresponding energy level diagrams are shown in Fig. 7 and 8. In energy diagrams, width of each emission band is adjusted according to the intensity of the band received from the emission spectra.

3.1.1. Fs-laser-940 $\mathrm{nm}$ incident pump wavelength. Emissive bands are observed between 239-397 $\mathrm{nm}$ in UV/violet region; $474 \mathrm{~nm}$ (blue emission); $544 \mathrm{~nm}$ (green emission); $604 \mathrm{~nm}, 670 \mathrm{~nm}$ and $718 \mathrm{~nm}$ (red emission bands) in visible region (Fig. 7(a)-i). The energy level diagram with respect to the observed emission wavelengths has been drawn and shown in Fig. 7(a)-ii which states three direct energy transfers from sensitizer $\left(2 \mathrm{~F}_{5 / 2}\right)$ to activator ion $\left(4 \mathrm{~F}_{7 / 2}\right.$ and $\left.4 \mathrm{~F}_{9 / 2}\right)$ and thereafter it passes through the different transitions within electronic states of $\mathrm{Er}^{3+}$ ion. Three major energy transfer occurred and can be represented as, (i) $2 \mathrm{~F}_{5 / 2}\left(\mathrm{Yb}^{3+}\right) \rightarrow 4 \mathrm{~F}_{7 / 2}\left(\mathrm{Er}^{3+}\right)$; (ii) $2 \mathrm{~F}_{5 / 2}\left(\mathrm{Yb}^{3+}\right.$ ) $\rightarrow 4 \mathrm{~F}_{9 / 2}\left(\mathrm{Er}^{3+}\right)$ and (iii) $2 \mathrm{~F}_{5 / 2}\left(\mathrm{Yb}^{3+}\right) \rightarrow 4 \mathrm{G}_{11 / 2}\left(\mathrm{Er}^{3+}\right)$, with a total of three non-radiative relaxations such as, $4 \mathrm{G}_{11 / 2}\left(\mathrm{Er}^{3+}\right) \rightarrow 2 \mathrm{H}_{9 /}$
${ }_{2}\left(\mathrm{Er}^{3+}\right), 4 \mathrm{~F}_{7 / 2}\left(\mathrm{Er}^{3+}\right) \rightarrow 2 \mathrm{H}_{11 / 2}\left(\mathrm{Er}^{3+}\right), 2 \mathrm{H}_{11 / 2}\left(\mathrm{Er}^{3+}\right) \rightarrow 4 \mathrm{~S}_{3 / 2}\left(\mathrm{Er}^{3+}\right)$, respectively.

3.1.2. Fs-laser $950 \mathrm{~nm}$ incident pump wavelength. During the interaction of UCN-PNs and Fs-laser $950 \mathrm{~nm}$ excitation source, emissive bands are obtained in between $265-432 \mathrm{~nm}$ of UV/violet regions; $455 \mathrm{~nm}$ (blue emission); $493 \mathrm{~nm}$ (intermediate region); $540 \mathrm{~nm}$ (green emission); $602 \mathrm{~nm}, 669 \mathrm{~nm}$ and $722 \mathrm{~nm}$ (red emissions) in visible regions (Fig. 7(b)-i). Intensities of bands in lower wavelengths (265-493 $\mathrm{nm}$ ) appeared to be weak compared to the green and red emissions but definitely with few numbers. The energy level diagram is shown in Fig. 7(b)-ii three direct energy transfers and following energy transitions, (i) $2 \mathrm{~F}_{5 / 2}\left(\mathrm{Yb}^{3+}\right) \rightarrow 4 \mathrm{~F}_{7 / 2}\left(\mathrm{Er}^{3+}\right)$; (ii) $2 \mathrm{~F}_{5 / 2}\left(\mathrm{Yb}^{3+}\right) \rightarrow 4 \mathrm{~F}_{9 /}$ ${ }_{2}\left(\mathrm{Er}^{3+}\right)$ and (iii) $2 \mathrm{~F}_{5 / 2}\left(\mathrm{Yb}^{3+}\right) \rightarrow 2 \mathrm{H}_{9 / 2}\left(\mathrm{Er}^{3+}\right)$, with a total of five non-radiative relaxations, $4 \mathrm{G}_{11 / 2}\left(\mathrm{Er}^{3+}\right) \rightarrow 2 \mathrm{H}_{9 / 2}\left(\mathrm{Er}^{3+}\right), 2 \mathrm{H}_{9 /}$ ${ }_{2}\left(\mathrm{Er}^{3+}\right) \rightarrow 4 \mathrm{~F}_{3 / 2}\left(\mathrm{Er}^{3+}\right), 4 \mathrm{~F}_{3 / 2}\left(\mathrm{Er}^{3+}\right) \rightarrow 4 \mathrm{~F}_{5 / 2}\left(\mathrm{Er}^{3+}\right), 4 \mathrm{~F}_{7 / 2}\left(\mathrm{Er}^{3+}\right) \rightarrow$ $2 \mathrm{H}_{11 / 2}\left(\mathrm{Er}^{3+}\right), 2 \mathrm{H}_{11 / 2}\left(\mathrm{Er}^{3+}\right) \rightarrow 4 \mathrm{~S}_{3 / 2}\left(\mathrm{Er}^{3+}\right)$.

3.1.3. Fs-laser $960 \mathrm{~nm}$ incident pump wavelength. Once UCN-PNs was interacted with Fs-laser (960 nm), emissive bands
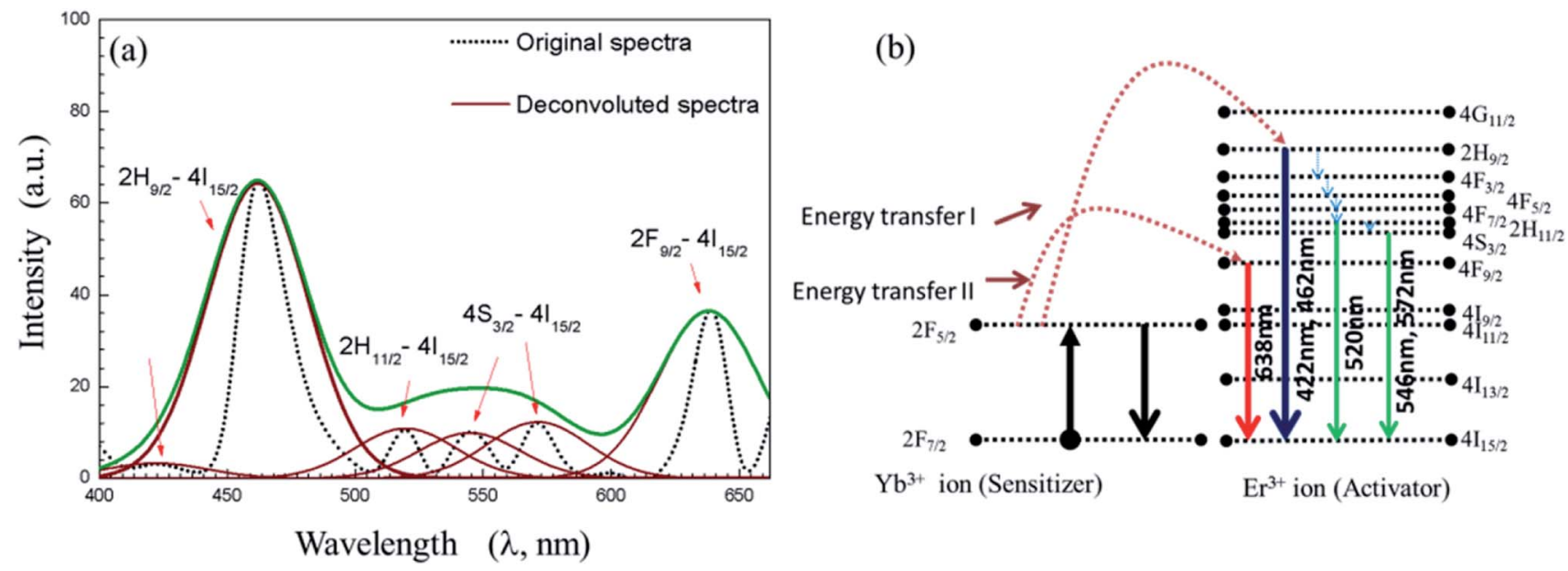

Fig. 6 (a) Photoluminescence (PL) spectra of colloidal UCN-PNs sample obtained with $450 \mathrm{~nm}$ excitation wavelength (b) energy diagram drawn from PL emission spectra in (a). 

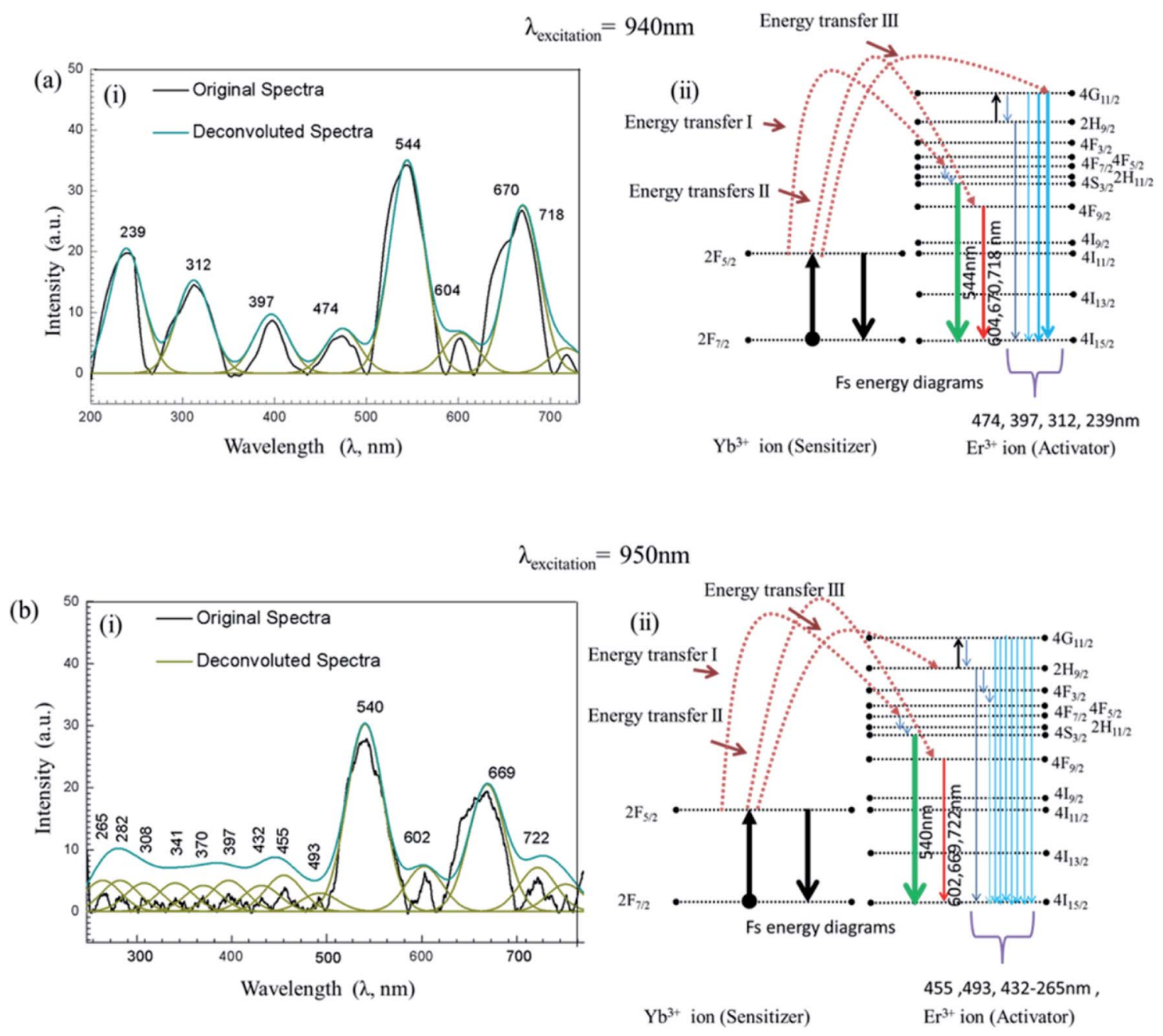

Fig. 7 Upconversion luminescence spectra and their corresponding energy diagram with femtosecond (Fs) arrangement. (a) Spectra (i) and energy level diagram (ii) under $940 \mathrm{~nm}$; (b) spectra (i) and energy level diagram (ii) under $950 \mathrm{~nm}$; excitation wavelengths.

obtained between 282-400 $\mathrm{nm}$ in UV/violet region; $465 \mathrm{~nm}$ (blue emission); $545 \mathrm{~nm}$ (green emission); $604 \mathrm{~nm}, 669 \mathrm{~nm}$ and $721 \mathrm{~nm}$ (red emissions) in visible regions (Fig. 8(a)-i). Intensities of bands in lower wavelengths $(282-465 \mathrm{~nm})$ are appeared to be weak compared to the green and red emissions. Green and red emissions obtained in the same intensity. The corresponding energy level diagram is shown in Fig. 8(a)-ii with three direct energy transfers, such as (i) $2 \mathrm{~F}_{5 / 2}\left(\mathrm{Yb}^{3+}\right) \rightarrow 4 \mathrm{~F}_{7 / 2}\left(\mathrm{Er}^{3+}\right)$; (ii) $2 \mathrm{~F}_{5 / 2}\left(\mathrm{Yb}^{3+}\right) \rightarrow$ $4 \mathrm{~F}_{9 / 2}\left(\mathrm{Er}^{3+}\right)$ and (iii) $2 \mathrm{~F}_{5 / 2}\left(\mathrm{Yb}^{3+}\right) \rightarrow 2 \mathrm{H}_{9 / 2}\left(\mathrm{Er}^{3+}\right)$, similar to $950 \mathrm{~nm}$, differing only with number of non-radiative relaxations following the energy transfer path, $4 \mathrm{G}_{11 / 2}\left(\mathrm{Er}^{3+}\right) \rightarrow 2 \mathrm{H}_{9 / 2}\left(\mathrm{Er}^{3+}\right), 4 \mathrm{~F}_{7 / 2}\left(\mathrm{Er}^{3+}\right) \rightarrow$ $2 \mathrm{H}_{11 / 2}\left(\mathrm{Er}^{3+}\right)$, and $2 \mathrm{H}_{11 / 2}\left(\mathrm{Er}^{3+}\right) \rightarrow 4 \mathrm{~S}_{3 / 2}\left(\mathrm{Er}^{3+}\right)$.

3.1.4 Fs-laser $970 \mathrm{~nm}$ incident pump wavelength. UCN-PNs were also interacted with Fs-laser with $970 \mathrm{~nm}$ irradiation and emissive bands obtained in between $241-447 \mathrm{~nm}$ in UV/violet regions; $463 \mathrm{~nm}$ (blue emission); $490 \mathrm{~nm}$ (intermediate region); $540 \mathrm{~nm}$ (green emission); $602 \mathrm{~nm}, 655 \mathrm{~nm}$ and $721 \mathrm{~nm}$ (red emissions) in visible regions (Fig. 8(b)-i). Emission bands appeared in lower wavelengths (241-490 nm) are quite strong in intensity; even one high intensity band is appeared with $241 \mathrm{~nm}$ peak position in UV region. These emission bands can be explained with separate energy band diagram in Fig. 8(b)-ii. Emission occurred due to three direct energy transfers between the different energy levels, such as (i) $2 \mathrm{~F}_{5 / 2}\left(\mathrm{Yb}^{3+}\right) \rightarrow 4 \mathrm{~F}_{7 / 2}\left(\mathrm{Er}^{3+}\right)$; (ii) $2 \mathrm{~F}_{5 / 2}\left(\mathrm{Yb}^{3+}\right) \rightarrow 4 \mathrm{~F}_{9 / 2}\left(\mathrm{Er}^{3+}\right)$ and (iii) $2 \mathrm{~F}_{5 / 2}\left(\mathrm{Yb}^{3+}\right) \rightarrow 4 \mathrm{G}_{11 / 2}\left(\mathrm{Er}^{3+}\right)$, including five non-radiative relaxations, $4 \mathrm{G}_{11 / 2}\left(\mathrm{Er}^{3+}\right) \rightarrow 2 \mathrm{H}_{9 / 2}$ $\left(\mathrm{Er}^{3+}\right), 2 \mathrm{H}_{9 / 2}\left(\mathrm{Er}^{3+}\right) \rightarrow 4 \mathrm{~F}_{3 / 2}\left(\mathrm{Er}^{3+}\right), 4 \mathrm{~F}_{3 / 2}\left(\mathrm{Er}^{3+}\right) \rightarrow 4 \mathrm{~F}_{5 / 2}\left(\mathrm{Er}^{3+}\right), 4 \mathrm{~F}_{7 / 2}$ $\left(\mathrm{Er}^{3+}\right) \rightarrow 2 \mathrm{H}_{11 / 2}\left(\mathrm{Er}^{3+}\right)$ and $2 \mathrm{H}_{11 / 2}\left(\mathrm{Er}^{3+}\right) \rightarrow 4 \mathrm{~S}_{3 / 2}\left(\mathrm{Er}^{3+}\right)$.

3.1.5 Fs-laser $980 \mathrm{~nm}$ incident pump wavelength. Finally, to compare the upconversion of UCN-PNs obtained after interaction with CW-980 nm NIR, the same sample interacted with the Fs-laser with $\lambda=980 \mathrm{~nm}$. Once interacted with Fs-laser the upconversion emissive bands are observed between 243-402 $\mathrm{nm}$ (in UV/violet regions); $473 \mathrm{~nm}$ (blue emission); $541 \mathrm{~nm}$ (green emission); $603 \mathrm{~nm}, 660 \mathrm{~nm}$ and $719 \mathrm{~nm}$ (red emissions) in visible regions (Fig. 8(c)-i). A very high intensity band is observed in UV region compared to others. The energy level diagram is shown in Fig. 8(c)ii with three direct energy transfers such as, (i) $2 \mathrm{~F}_{5 / 2}\left(\mathrm{Yb}^{3+}\right) \rightarrow 4 \mathrm{~F}_{7 /}$ ${ }_{2}\left(\mathrm{Er}^{3+}\right)$; (ii) $2 \mathrm{~F}_{5 / 2}\left(\mathrm{Yb}^{3+}\right) \rightarrow 4 \mathrm{~F}_{9 / 2}\left(\mathrm{Er}^{3+}\right)$ and (iii) $2 \mathrm{~F}_{5 / 2}\left(\mathrm{Yb}^{3+}\right) \rightarrow 4 \mathrm{G}_{11 /}$ ${ }_{2}\left(\mathrm{Er}^{3+}\right)$, with three non-radiative relaxations, (i) $4 \mathrm{G}_{11 / 2}\left(\mathrm{Er}^{3+}\right) \rightarrow 2 \mathrm{H}_{9 /}$ 

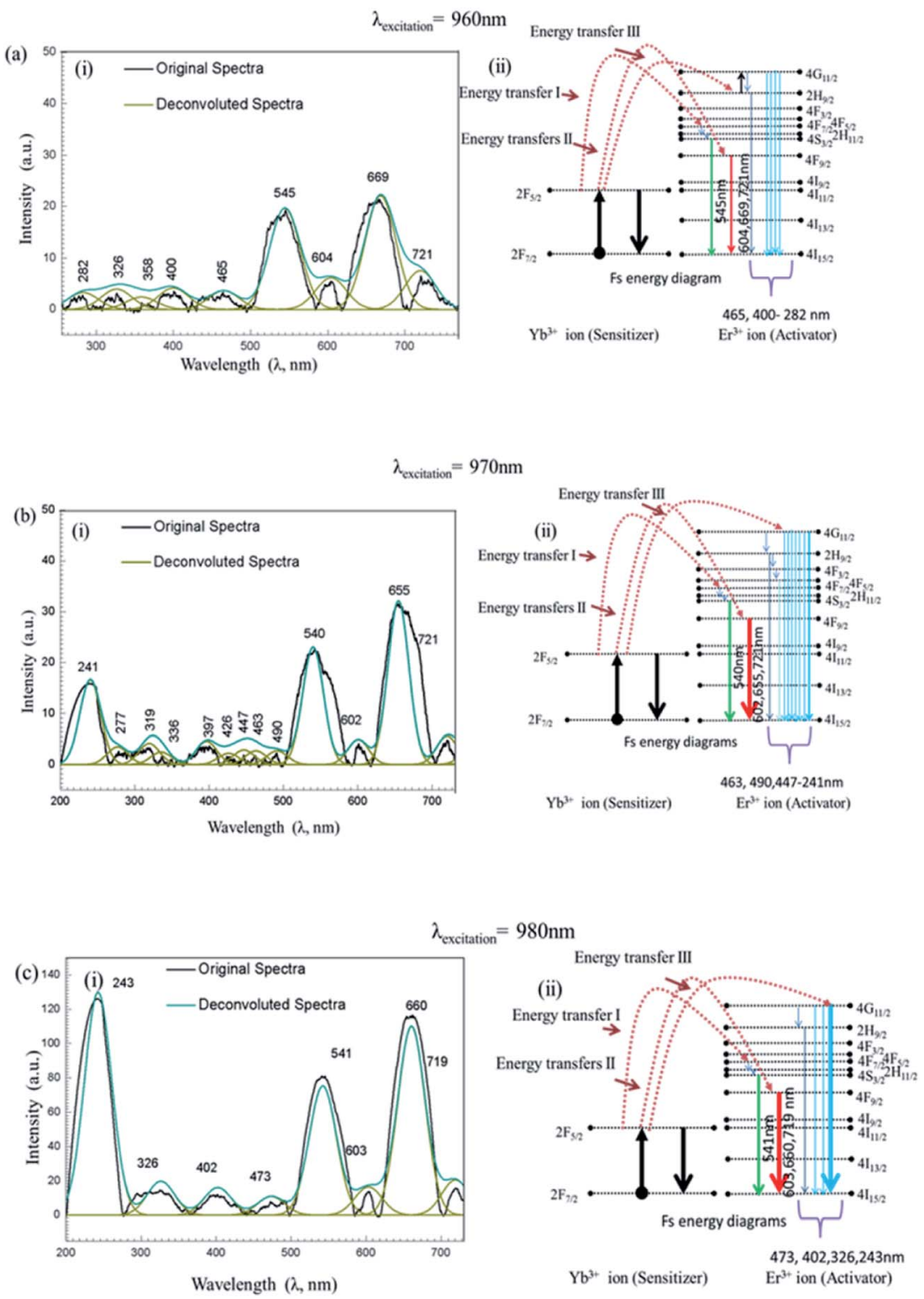

Fig. 8 Upconversion luminescence spectra and their corresponding energy diagram with femtosecond (Fs) arrangement. (a) Spectra (i) and energy band diagram (ii) under $960 \mathrm{~nm}$; (b) spectra (i) and energy level diagram (ii) under $970 \mathrm{~nm}$; (c) spectra (i) and diagram (ii) under $980 \mathrm{~nm}$ excitation wavelengths.

${ }_{2}\left(\mathrm{Er}^{3+}\right)$, (ii) $4 \mathrm{~F}_{7 / 2}\left(\mathrm{Er}^{3+}\right) \rightarrow 2 \mathrm{H}_{11 / 2}\left(\mathrm{Er}^{3+}\right)$ and (iii) $2 \mathrm{H}_{11 / 2}\left(\mathrm{Er}^{3+}\right) \rightarrow 4 \mathrm{~S}_{3 /}$ ${ }_{2}\left(\mathrm{Er}^{3+}\right)$. Thus, five emission spectra in Fig. 7 and 8 revealed the high energy emissions under different excitation wavelengths, which never been observed for CW-NIR laser (980 nm). Among five of them, the highest UV emission ( $\left.\mathrm{UV}_{\text {full }}\right)$ was found under $980 \mathrm{~nm}$ excitation wavelength. Apart from that, the other emissions green $(\mathrm{G}) /$ red (R) are also significant and appear with highest intensity in case of $980 \mathrm{~nm}$ excitation wavelength. Blue emissions are also observed in each of the cases.

Furthermore, intensity ratios between UV, R and G under Fslaser treatment were calculated for five different excitation wavelengths and are shown in Fig. 9. Intensity changes for different emissions (UV, G and R) under different excitation wavelengths (940 nm, $950 \mathrm{~nm}, 960 \mathrm{~nm}, 970 \mathrm{~nm}$ and $980 \mathrm{~nm}$ ) resulted in different relative ratio plots $\mathrm{UV}_{\text {full }} / \mathrm{G} ; \mathrm{UV}_{\text {full }} / \mathrm{R}_{\text {full }} ; \mathrm{G} / \mathrm{R} 1$, G/R2, G/R3; and G/R $R_{\text {full }}$ shown in Fig. 9(a)-(d), respectively. Different in efficient population of photons in different energy levels under 940-980 nm excitation sources could be the possible reasons for the occurrence of different intensity.

\subsection{Discussion}

It can be mentioned that the $\alpha$ and $\beta \mathrm{NaYF}_{4 \mathrm{c}}$ nanocrystals produce with a delayed nucleation during synthesis. Hence, reaction time and temperature play an important role in obtaining different $\mathrm{NaYF}_{4}$ nanopolyhedra. The UCN crystal growth follows by four sequential stages such as (i) delayed nucleation, (ii) particle-growth, (iii) shrinkage and (iv) aggregation. ${ }^{\mathbf{4 8 , 4 9}}$ In stage I: in this stage, with prolonging reaction 

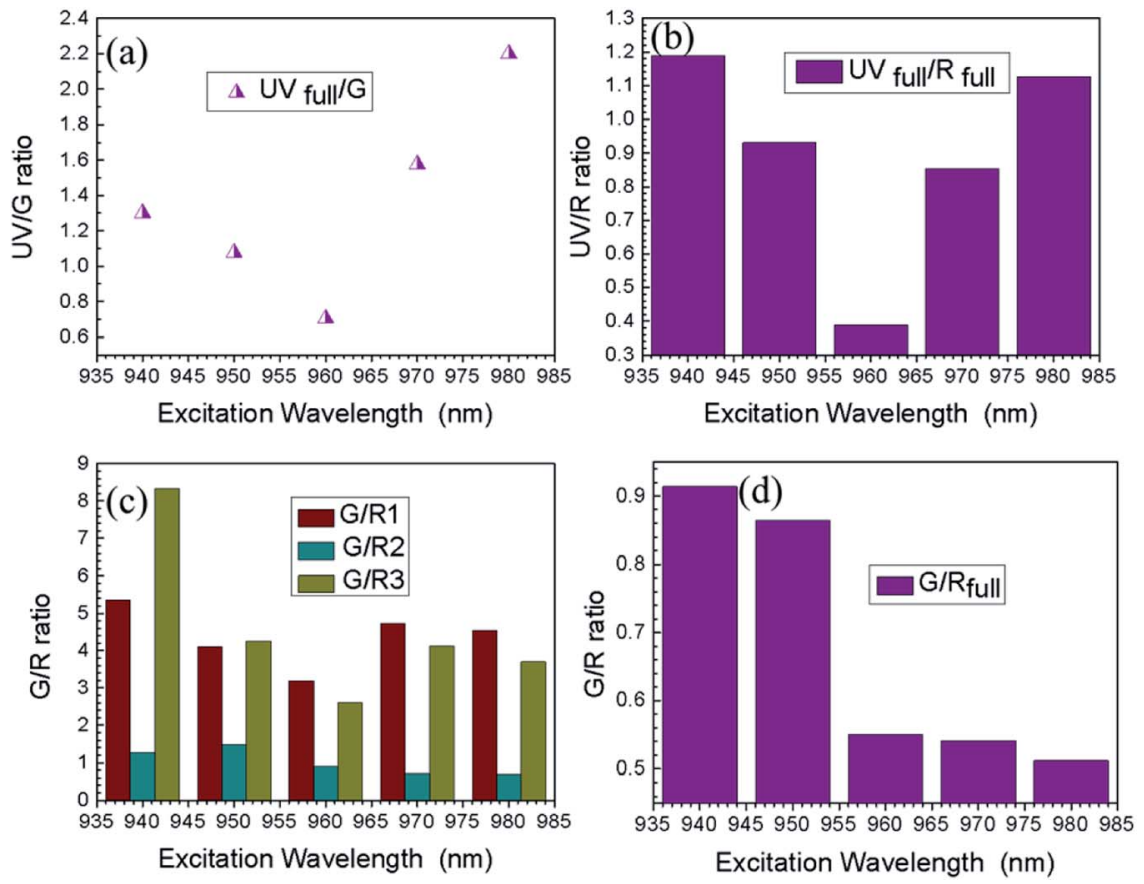

Fig. 9 Shows the ratio plots for the intensity of different emission: (a) $U V_{\text {full }} / G$, (b) $U V_{\text {full }} / R_{\text {full }}$; (c) G/R1, G/R2, G/R3; (d) G/R full $v s$. excitation wavelengths.

time, $\alpha$-phases start to appear and up to a certain period ( $\sim 0 \mathrm{~min}$ ) nanocrystal size increases. Hence co-precipitating reaction between sodium fluoride and lanthanide precursors helps to form the $\alpha$-phases and after that the monomer concentration increases. In stage: II: at initial period, the monomer concentration becomes high and after certain interval the monomers become exhausted and their sizes do not increase further and finally $\alpha-\mathrm{NaYF}_{4}$ dissolves. Stage: III: during third stage, the nanocrystals redispersed by strong coordination between nanocrystal surface and ligands of organic compounds (OA, 1-ODE). Under this condition, small truncated cubes formed. Stage IV: in this stage a non-uniform aggregates are formed from small nanocubes due to higher surface energy and attractive forces from surface-ligands. Now, continuing the reaction the phases-transition between $\alpha$ - to $\beta$-phase takes place through the Ostwald-ripening enhanced process in presence of selective lanthanide elements; $\mathrm{Y}$ and elements in between (Dy-Lu):Yb,Er. ${ }^{48,49}$

However, binding of $\mathrm{N}-\mathrm{H}$ groups (as their existence were assured by both Raman and FTIR spectra) to nanocrystal surface, presence of van der Waals forces interaction between nanocrystals surface and oleic-acid ligand, strong co-ordination interaction between nanocrystal surface and several cappinggroups could be the possible reasons of pearl-necklace patterned - morphological evolution.

It can be noted that upconversion luminescence properties with Fs-laser irradiation for different rare earth elements along with their applications were reported elsewhere. ${ }^{50-58}$ Such as YVO4 single crystal upconversion luminescence was observed under infrared (IR) Fs-irradiation which resulted in broad characteristic emission in visible region $(350-600 \mathrm{~nm}) .{ }^{50}$ For,
$\mathrm{Ce}^{3+}$ doped YAP crystal, upconversion luminescence appeared in both ultraviolet and visible region under a focused $800 \mathrm{~nm}$ Fs-laser irradiation. ${ }^{51}$ Visible emission bands were also found with $\mathrm{NaYF}_{4}$-glass ceramic doped with $\mathrm{Er}^{3+}$ ions under $800 \mathrm{~nm}$ CW laser treatment. ${ }^{52}$ Intracellular imaging of cancer cells (such as HeLa cells, cervical cancer cells, collected on 8 Feb, 1951 from Henrietta Lacks), by using the Fs-pulse laser (100 Fs, $920 \mathrm{~nm}$ ) was performed with very high resolution using nonfunctionalized $\mathrm{NaYF}_{4}: \mathrm{Er}^{3+}, \mathrm{Yb}^{3+} .{ }^{33}$ Further, red and green upconversion luminescence was reported with $5 \% \mathrm{Er}^{3+}$ doped $\mathrm{NaYF}_{4}$ nanocrystals with using two Fs-laser (excitation wavelengths $800 \mathrm{~nm}, 1490 \mathrm{~nm}$ ) simultaneously. ${ }^{55}$ Tunable enhanced ultraviolet luminescence can be developed by using UCNPs for recording highly effective and rapid in situ-real time biocompatible photoactivation..$^{54}$ Optogenetic proteins have huge applications in neurology and brain science along with cell biology. However, it was found that the narrow excitation wavelength limits the applications of optogenetics which has recently manipulated and improved using tunable Fs-laser system. ${ }^{59}$ Moreover, for ultra-deep in vivo bio-imaging nonlinear optical effects using Fs-laser excitation in AIEgen nanocrystals was found effective. ${ }^{60}$ By a group of researchers, it is reported that Ti:Sapphire Fs-laser, with pulse duration of about $160 \mathrm{fs}$, is very useful for generation of high harmonic as example fifth harmonic generation from photonic crystal and is useful in designing opto-electronic devices with effectively high efficiency. ${ }^{58}$ Further, it can be noted that for the rare-earth doped luminescent nanomaterials, colour tuning is having important significance for several applications such as designing of display device, bio-labeling, optoelectronic device etc. The tuned luminescence properties can be developed from $\mathrm{Er}^{3+}$ 
doped glass ceramic using $800 \mathrm{~nm}$ Fs-laser excitation sources. ${ }^{\mathbf{6 1}}$ Thus, the present findings i.e., the development of UCN-PNs and their improved luminescence properties in UV and visible ranges are very interesting and can be used in device making for industrial (optoelectronics) to biomedical such as for disease diagnosis and therapeutic applications by targeting the infected cells with enhanced efficiency.

\section{Summary and conclusions}

In this work, $\mathrm{NaYF}_{4}$ nanonecklaces (UCN-PNs) with lanthanides $\left(\mathrm{Yb}^{3+}, \mathrm{Er}^{3+}\right)$ have been synthesized for the first time with one pot chemical synthesis approach, by controlling the reaction temperature in in situ condition, without adding any external polymeric components during synthesis process. UCN-PNs contain both of the $\alpha$ - and $\beta$-phase within its solid structure and are very stable. Presence of these two phases in UCN-NPs could be the cause of high energy upconversion and make them very seminal and are with caterpillar/necklace type of structure.

This self-assembled pearl-necklaces type structural -network may be allowed for designing 2D nanostructures with defining clear geometry.

Apart from that, the bright blue emission make them very attractive with lower excitation wavelength source with visible to visible upconversion. ${ }^{\mathbf{1 0 , 6 2}}$ With higher wavelength source with Fs-laser, UV emission becomes prominent making them a suitable candidate for industrial and biomedical applications. ${ }^{63-65}$ The different emissions (green/red/blue/cyan/UV) could be useful in colour tuning and magnetic sorting ${ }^{\mathbf{6 6 , 6 7}}$ by changing their excitation wavelengths.

\section{Conflicts of interest}

There are no conflicts to declare.

\section{Acknowledgements}

Authors acknowledge the financial support awarded to P. Paik by DST-Nanomission, India (ref: SR/NM/NS-1005/2015), Science and Engineering Research Board, India (ref: EEQ/2016/000040). M. D. Modak acknowledges the DST INSPIRE fellowship (IVR No. 201400000480, No. DST/INSPIRE Fellowship/2015/ IF150215), Department of Science and Technology, Ministry of Science and Technology for pursuing PhD. Authors also want to acknowledge Defence Research and Development Organizations (DRDO) , Ministry of Defence , and Government of India (ERIP/ER/1501138/M/01/319/D(RD)) for providing Femtosecond - laser facility.

\section{Notes and references}

1 D. Astruc, E. Boisselier and C. Ornelas, Chem. Rev., 2010, 110, 1857-1959.

2 C. C. Lee, J. A. MacKay, J. M. J. Fréchet and F. C. Szoka, Nat. Biotechnol., 2005, 23, 1517-1526.
3 L. Wang, R. Yan, Z. Huo, L. Wang, J. Zeng, J. Bao, X. Wang, Q. Peng and Y. Li, Angew. Chem., Int. Ed., 2005, 44, 60546057.

4 C. ZHANG, L. SUN, Y. ZHANG and C. YAN, J. Rare Earths, 2010, 28, 807-819.

5 M. Wang, G. Abbineni, A. Clevenger, C. Mao and S. Xu, Nanomedicine, 2011, 7, 710-729.

6 G. Yi, H. Lu, S. Zhao, Y. Ge, W. Yang, D. Chen and L.-H. Guo, Nano Lett., 2004, 4, 2191-2196.

7 G. Chen, H. Qiu, P. N. Prasad and X. Chen, Chem. Rev., 2014, 114, 5161-5214.

8 T. V. Esipova, X. Ye, J. E. Collins, S. Sakadžić, E. T. Mandeville, C. B. Murray and S. A. Vinogradov, Proc. Natl. Acad. Sci. U. S. A., 2012, 109, 20826-20831.

9 L. Wang and Y. Li, Chem. Commun., 2006, 2557-2559.

10 Q. Liu, T. Yang, W. Feng and F. Li, J. Am. Chem. Soc., 2012, 134, 5390-5397.

11 Z. Li, Y. Zhang and S. Jiang, Adv. Mater., 2008, 20, 4765-4769. 12 F. Wang and X. Liu, J. Am. Chem. Soc., 2008, 130, 5642-5643. 13 V. Muhr, C. Würth, M. Kraft, M. Buchner, A. J. Baeumner, U. Resch-Genger and T. Hirsch, Anal. Chem., 2017, 89, 4868-4874.

14 C. Hazra, V. N. K. B. Adusumalli and V. Mahalingam, ACS Appl. Mater. Interfaces, 2014, 6, 7833-7839.

15 Y. Ma, S. Huang, M. Deng and L. Wang, ACS Appl. Mater. Interfaces, 2014, 6, 7790-7796.

16 D. K. Chatterjee, M. K. Gnanasammandhan and Y. Zhang, Small, 2010, 6, 2781-2795.

17 L. Y. Ang, M. E. Lim, L. C. Ong and Y. Zhang, Nanomedicine, 2011, 6, 1273-1288.

18 L.-L. Li, H.-W. An, B. Peng, R. Zheng and H. Wang, Mater. Horiz., 2019, 6, 1794-1811.

19 G. Pandit, K. Roy, U. Agarwal and S. Chatterjee, ACS Omega, 2018, 3, 3143-3155.

20 S. Whitelam and R. L. Jack, Annu. Rev. Phys. Chem., 2015, 66, 143-163.

21 A. Saini, R. Kaur, N. Singh, A. Kuwar and N. Kaur, ACS Appl. Bio Mater., 2019, 2, 135-143.

22 M. Dolci, D. Toulemon, Z. Chaffar, J.-L. Bubendorff, F. Tielens, M. Calatayud, S. Zafeiratos, S. Begin-Colin and B. P. Pichon, ACS Appl. Nano Mater., 2019, 2, 554-565.

23 D. Perahia, R. Traiphol and U. H. F. Bunz, Macromolecules, 2001, 34, 151-155.

24 M.-C. Daniel and D. Astruc, Chem. Rev., 2004, 104, 293-346. 25 C. Wang, L. Cheng and Z. Liu, Theranostics, 2013, 3, 317-330. 26 C. Wang, H. Tao, L. Cheng and Z. Liu, Biomaterials, 2011, 32, 6145-6154.

27 Q. Chen, C. Wang, L. Cheng, W. He, Z. Cheng and Z. Liu, Biomaterials, 2014, 35, 2915-2923.

28 C.-X. Huang, H.-J. Chen, F. Li, W.-N. Wang, D.-D. Li, X.-Z. Yang, Z.-H. Miao, Z.-B. Zha, Y. Lu and H.-S. Qian, J. Mater. Chem. B, 2017, 5, 9487-9496.

29 K. Liu, L. Dong, Y. Xu, X. Yan, F. Li, Y. Lu, W. Tao, H. Peng, Y. Wu, Y. Su, D. Ling, T. He, H. Qian and S.-H. Yu, Biomaterials, 2018, 158, 74-85.

30 J.-C. Boyer, L. A. Cuccia and J. Capobianco, Nano Lett., 2007, 7, 847-852. 
31 S. Heer, K. Kömpe, H. U. Güdel and M. Haase, Adv. Mater., 2004, 16, 2102-2105.

32 K. N. Reddy, M. A. H. Shareef and N. Pandaraiah, J. Mater. Sci. Lett., 1983, 2, 83-84.

33 H. Song, B. Sun, T. Wang, S. Lu, L. Yang, B. Chen, X. Wang and X. Kong, Solid State Commun., 2004, 132, 409-413.

34 M. Lee, Y. H. Park, E. B. Kang, A. Chae, Y. Choi, S. Jo, Y. J. Kim, S.-J. Park, B. Min, T. K. An, J. Lee, S.-I. In, S. Y. Kim, S. Y. Park and I. In, ACS Omega, 2017, 2, 70967105.

35 D. T. Klier and M. U. Kumke, J. Mater. Chem. C, 2015, 3, 11228-11238.

36 X. Luo and K. Akimoto, Appl. Surf. Sci., 2013, 273, 257-260.

37 C. Renero-Lecuna, R. Martín-Rodríguez, R. Valiente, J. González, F. Rodríguez, K. W. Krämer and H. U. Güdel, Chem. Mater., 2011, 23, 3442-3448.

38 H. Assaaoudi, G.-B. Shan, N. Dyck and G. P. Demopoulos, CrystEngComm, 2013, 15, 4739-4746.

39 S. Wilhelm, T. Hirsch, W. M. Patterson, E. Scheucher, T. Mayr and O. S. Wolfbeis, Theranostics, 2013, 3, 239-248.

40 Z. Li, H. Miao, Y. Fu, Y. Liu, R. Zhang and B. Tang, Nanoscale Res. Lett., 2016, 11, 441.

41 M. He, P. Huang, C. Zhang, F. Chen, C. Wang, J. Ma, R. He and D. Cui, Chem. Commun., 2011, 47, 9510-9512.

42 J. A. Capobianco, F. Vetrone, J. C. Boyer, A. Speghini and M. Bettinelli, Opt. Mater., 2002, 19, 259-268.

43 H. Guo, N. Dong, M. Yin, W. Zhang, L. Lou and S. Xia, J. Phys. Chem. B, 2004, 108, 19205-19209.

44 M. Nyk, R. Kumar, T. Y. Ohulchanskyy, E. J. Bergey and P. N. Prasad, Nano Lett., 2008, 8, 3834-3838.

45 G. Chen, T. Y. Ohulchanskyy, R. Kumar, H. Ågren and P. N. Prasad, ACS Nano, 2010, 4, 3163-3168.

46 T.-Y. Hsieh, W.-C. Huang, Y.-D. Kang, C.-Y. Chu, W.-L. Liao, Y.-Y. Chen and S.-Y. Chen, Adv. Healthcare Mater., 2016, 5, 3016-3026.

47 A. Xia, Y. Gao, J. Zhou, C. Li, T. Yang, D. Wu, L. Wu and F. Li, Biomaterials, 2011, 32, 7200-7208.

48 N. T. K. Thanh, N. Maclean and S. Mahiddine, Chem. Rev., 2014, 114, 7610-7630.

49 H.-X. Mai, Y.-W. Zhang, L.-D. Sun and C.-H. Yan, J. Phys. Chem. C, 2007, 111, 13730-13739.

50 L. Yang, C. Wang, Y. Dong, N. Da, X. Hu, D. Chen and J. Qiu, Opt. Express, 2005, 13, 10157-10162.
51 L. Yang, Y. Dong, D. Chen, C. Wang, X. Hu, N. Da, G. Zhao, J. Xu, X. Jiang, C. Zhu and J. Qiu, Opt. Express, 2006, 14, 243247.

52 X. Shang, P. Chen, T. Jia, D. Feng, S. Zhang, Z. Sun and J. Qiu, Phys. Chem. Chem. Phys., 2015, 17, 11481-11489.

53 F. Vetrone, R. Naccache, A. de la Fuente, F. Sanz-Rodríguez, A. Blazquez-Castro, E. M. Rodriguez, D. Jaque, J. G. Solé and J. A. Capobianco, Nanoscale, 2010, 2, 495-498.

54 J. Shen, G. Chen, T. Y. Ohulchanskyy, S. J. Kesseli, S. Buchholz, Z. Li, P. N. Prasad and G. Han, Small, 2013, 9, 3213-3217.

55 X. Shang, P. Chen, W. Cheng, K. Zhou, J. Ma, D. Feng, S. Zhang, Z. Sun, J. Qiu and T. Jia, J. Appl. Phys., 2014, 116, 063101.

56 Y. Dong, J. Xu, G. Zhou, G. Zhao, M. Jie, L. Y. Yang, L. Su, J. Qiu, W. Feng and L. lin, Opt. Express, 2006, 14, 1899-1904.

57 M. H. Yuan, H. H. Fan, Q. F. Dai, S. Lan, X. Wan and S. L. Tie, Opt. Express, 2015, 23, 21909-21918.

58 P. Tzankov, O. Steinkellner, J. Zheng, M. Mero, W. Freyer, A. Husakou, I. Babushkin, J. Herrmann and F. Noack, Opt. Express, 2007, 15, 6389-6395.

59 W. Ji, S. Wang, J. Zhao, Y. Tian, H. Pan, B. Zheng, M. Yang, H. Tian, M. Hu, H. Wang and J. Chang, J. Appl. Phys., 2019, 125, 163105.

60 Z. Zheng, D. Li, Z. liu, H.-Q. Peng, H. H.-Y. Sung, R. T. K. Kwok, I. D. Williams, J. W. Y. Lam, J. Qian and B. Z. Tang, Adv. Mater., 2019, 31, 1904799.

61 L.-Z. Deng, Y.-H. Yao, L. Deng, H.-Y. Jia, Y. Zheng, C. Xu, J.-P. Li, T.-Q. Jia, J.-R. Qiu, Z.-R. Sun and S.-A. Zhang, Front. Phys., 2018, 14, 13602.

62 O. S. Kwon, H. S. Song, J. Conde, H. Il Kim, N. Artzi and J. H. Kim, ACS Nano, 2016, 10, 1512-1521.

63 B. Del Rosal and D. Jaque, Methods Appl. Fluoresc., 2019, 7, 022001.

64 Y. Liu, X. Meng and W. Bu, Coord. Chem. Rev., 2019, 379, 8298.

65 G. Yi, H. Lu, S. Zhao, Y. Ge, W. Yang, D. Chen and L. H. Guo, Nano Lett., 2004, 4, 2191-2196.

66 J. H. Kim, F. Deng, F. N. Castellano and J. H. Kim, ACS Photonics, 2014, 1, 382-388.

67 X. Zhang, Z. Zhang, Z. Liu, C. Zhang, B. Zhang, X. Mi and H. Zheng, J. Lumin., 2019, 205, 374-379. 